\title{
Predicting therapeutic efficacy of endocrine therapy for stage IV breast cancer by tumor-infiltrating lymphocytes
}

\author{
YUKA ASANO $^{1}$, SHINICHIRO KASHIWAGI ${ }^{1}$, WATARU GOTO $^{1}$, KOJI TAKADA $^{1}$, \\ KATSUYUKI TAKAHASHI ${ }^{2}$, MASATSUNE SHIBUTANI ${ }^{3}$, RYOSUKE AMANO ${ }^{4}$, \\ TSUTOMU TAKASHIMA $^{1}$, SHUHEI TOMITA ${ }^{2}$, KOSEI HIRAKAWA ${ }^{1,3}$ and MASAICHI OHIRA ${ }^{1,3}$ \\ Departments of ${ }^{1}$ Breast and Endocrine Surgery, ${ }^{2}$ Pharmacology, ${ }^{3}$ Gastrointestinal Surgery and \\ ${ }^{4}$ Hepato-Biliary-Pancreatic Surgery, Osaka City University Graduate School of Medicine, \\ Abeno-ku, Osaka 545-8585, Japan
}

Received May 5, 2019; Accepted November 5, 2019

DOI: $10.3892 / \mathrm{mco} .2020 .2063$

\begin{abstract}
The tumor immune environment not only modulates the effects of immunotherapy, but also the effects of other anticancer drugs and treatment outcomes. These immune responses may be evaluated by measuring tumor-infiltrating lymphocytes (TILs), which has been frequently verified clinically. In the present study, the prediction of the therapeutic effect of endocrine therapy by TILs on stage IV breast cancer was clinically analyzed. Data from 40 patients who underwent endocrine therapy as the initial drug therapy for stage IV breast cancer were used. The correlation between TILs, evaluated according to standard methods, and prognosis, including the efficacy of endocrine therapy, was investigated retrospectively. Patients with $\geq 50 \%$ lymphocytic infiltration were considered to have lymphocyte-predominant breast cancer (LPBC). An analysis of outcomes revealed no difference in progression-free survival ( $\mathrm{PFS} ; \mathrm{P}=0.171$ ), time to treatment failure (TTF; $\mathrm{P}=0.054)$, or overall survival $(\mathrm{OS} ; \mathrm{P}=0.641)$ between the high TIL $(>10 \%)$ and low TIL $(\leq 10 \%)$ groups. Patients with LPBC $(\geq 50 \%)$ exhibited a significant prolongation of PFS ( $P=0.005$, log-rank), TTF $(\mathrm{P}=0.001)$ and $\mathrm{OS}(\mathrm{P}=0.027)$ compared with non-LPBC patients. On receiver operating characteristics (ROC) curve analysis, better results were obtained with LPBCs [area under the curve (AUC) $=0.700$ ] than with TILs (AUC $=0.606$ ). The present findings suggest that a high level of lymphocytic infiltration in the tumor stroma may serve as a predictor of the therapeutic efficacy of endocrine therapy in patients with stage IV estrogen receptor-positive breast cancer.
\end{abstract}

Correspondence to: Dr Shinichiro Kashiwagi, Department of Breast and Endocrine Surgery, Osaka City University Graduate School of Medicine, 1-4-3 Asahi-machi, Abeno-ku, Osaka 545-8585, Japan

E-mail: spqv9ke9@view.ocn.ne.jp

Key words: tumor-infiltrating lymphocytes, endocrine therapy, breast cancer, stage IV, predictive marker

\section{Introduction}

Breast cancer with distant metastasis at first presentation (stage IV disease) is often encountered in the outpatient setting. With the recent advances in multimodal therapies for breast cancer, long-term survival may be expected, even in stage IV breast cancer with distant metastasis (1). However, one of the goals in treating metastatic disease is prolongation of survival while maintaining good quality of life (QOL). Endocrine therapy is suitable for this purpose. Adverse events are less severe with endocrine therapy compared with those with chemotherapy; therefore, due to its ability to maintain QOL, endocrine therapy is the preferred first-line treatment for non-life-threatening hormone receptor-positive advanced breast cancer (Hortobagyi's algorithm) (2). However, although endocrine therapy is useful for certain types of hormone receptor-positive breast cancer (HRBC), there are other types for which it is not very effective. In neoadjuvant endocrine therapy for early-stage breast cancer, the use of the preoperative endocrine prognostic index score and Ki67 as predictive markers has been reported $(3,4)$. However, few studies to date have investigated the prediction of the therapeutic effect of endocrine therapy in stage IV breast cancer. Stage IV breast cancer is advanced and, if it cannot be controlled with initial drug therapy, it is life-threatening. Therefore, the ability to predict therapeutic efficacy would be of considerable value for selecting the initial drug therapy (endocrine therapy or chemotherapy).

Cancer cells harbor various gene abnormalities that allow them to proliferate spontaneously and survive, but they are also affected by the surrounding environment, which is involved in the intrinsic characteristics of cancer (5). The tumor immune environment not only modulates the effects of immunotherapy, but also the effects of other anticancer drugs and treatment outcomes $(6,7)$. Thus, the importance of inhibiting and improving the tumor immune microenvironment is well-recognized. These immune responses may be evaluated by tumor-infiltrating lymphocytes (TILs), which has been demonstrated clinically (8-10). We also previously reported the prediction of the therapeutic efficacy of neoadjuvant chemotherapy (NAC) by TILs (11). The aim of the present study was 
to clinically verify the prediction of the therapeutic efficacy of endocrine therapy for stage IV breast cancer using TILs.

\section{Patients and methods}

Patient background. The same methods as those used in the present study were previously used to investigate the significance of NAC for early breast cancer (11-14). Data from 40 patients who underwent endocrine therapy as the initial drug therapy for stage IV breast cancer at Osaka City University Hospital between June 2004 and December 2013 were used. The median follow-up time was 155 weeks (range, 13-553 weeks). The overall response rate (ORR), clinical benefit rate (CBR), disease control rate (DCR), overall survival (OS), time to treatment failure (TTF) and progression-free survival (PFS) were calculated to determine the efficacy of this regimen. Additionally, tumor stage and $\mathrm{T}$ and $\mathrm{N}$ factors were stratified based on the TNM Classification of Malignant Tumors, Union for International Cancer Control (UICC), 7th edition (15). Breast cancer was histologically confirmed by core needle biopsy and staged by systemic imaging studies using computed tomography (CT), ultrasonography (US) and bone scintigraphy. Breast cancer was classified into subtypes according to the immunohistochemical expression of estrogen receptors (ERs), progesterone receptors (PgRs), human epidermal growth factor receptor (HER)2 and Ki67. Based on their immunohistochemical expression, the tumors were categorized into the following immunophenotypes: Luminal A (ER $\mathrm{ER}^{+}$and/or $\mathrm{PgR}{ }^{+}$, HER2-, Ki67-low), luminal B (ER ${ }^{+}$and/or PgR ${ }^{+}, \mathrm{HER}^{+}$; or $\mathrm{ER}^{+}$ and/or PgR ${ }^{+}$, HER2-, Ki67-high), HER2-enriched (HER2BC; $\mathrm{ER}^{-}, \mathrm{PgR}^{-}, \mathrm{HER}^{+}$) and triple-negative breast cancer (TNBC; $\mathrm{ER}^{-}, \mathrm{PgR}^{-}, \mathrm{HER} 2^{-}$) (16). In the present study, luminal A and $\mathrm{B}$ were considered as HRBC.

Endocrine therapy was administered on an outpatient basis in all cases. This protocol was repeated until progressive disease (PD) was detected or a severe adverse event requiring the discontinuation of the scheduled endocrine therapy was reported. The therapeutic antitumor effects were assessed according to the Response Evaluation Criteria in Solid Tumors (17). All clinical analyses in the present study were based on imaging assessment.

TTF was evaluated on a daily basis and was defined as the period from the date of treatment initiation to discontinuation for any reason, including disease progression, treatment toxicity and death. OS was evaluated on a weekly basis and was defined as the period from the date of treatment initiation to the date of death from any cause. PFS was evaluated on a weekly basis and was defined as the period from the date of treatment initiation to the date of death or the date of confirmation of PD.

Histopathological evaluation of TILs. Histopathological assessment for predictive factors was performed using core needle biopsy specimens at the time of breast cancer diagnosis. The histopathological parameters examined included nuclear grade, histological type, presence of TILs, and correlation of these parameters with intrinsic subtypes and pathological complete response. Histopathological analysis of the percentage of TILs was evaluated on a single full-face hematoxylin and eosin (HE)-stained tumor section using the criteria described by Salgado et al (18). TILs were defined as the infiltrating lymphocytes within the tumor stroma and were expressed as a proportion of the field investigated; additionally, the number of TILs in the stroma surrounding the stained cancer cells was quantitatively measured in each field at a magnification, x400 $(19,20)$. Areas of carcinoma in situ and crush artifacts were not included. Proportional scores were defined as 3, 2, 1 and 0 if the area of stroma with lymphoplasmacytic infiltration around invasive tumor cell nests was $>50,10-50, \leq 10 \%$ and absent, respectively (Fig. 1). TILs were considered 'high' for scores $\geq 2$, and 'low' for scores 1 and 0 . Patients with $\geq 50 \%$ lymphocytic infiltration were considered to have lymphocyte-predominant breast cancer (LPBC) (21). Histopathological evaluation of TILs was jointly performed by two breast pathologists who were blinded to clinical information, including treatment allocation and outcomes.

Statistical analysis. Statistical analysis was performed using SPSS version 19.0 (SPSS Inc.). The associations between TILs, LPBC and clinicopathological variables were analyzed using Chi-squared or Fisher's exact tests, as appropriate. OS, TTF and PFS were estimated using the Kaplan-Meier method and compared using log-rank tests. Univariate and multivariate hazard ratios (HRs) were computed for the study parameters with $95 \%$ confidence intervals (CIs) using a Cox proportional hazards model, and used in a backward stepwise method for variable selection in multivariate analyses. $\mathrm{P}<0.05$ was considered to indicate statistically significant differences.

Ethics approval. The present study was conducted at Osaka City University Graduate School of Medicine (Osaka, Japan), according to the Reporting Recommendations for Tumour Marker Prognostic Studies (REMARK) guidelines and following a retrospectively written research, pathological evaluation, and statistical plan (22). The research protocol conformed to the provisions of the Declaration of Helsinki as revised in 2013. All patients were informed of the investigational nature of the study and provided written informed consent. The study protocol was approved by the Ethics Committee of Osaka City University (approval no. 926).

\section{Results}

Endocrine therapy in stage IV breast cancer. The background characteristics of 40 patients who underwent endocrine therapy as the initial drug therapy for stage IV breast cancer are shown in Table I. All patients were women with a median age of 64 years (range, 44-88 years); the bone or soft tissue was the site of metastasis in 21 patients $(52.5 \%)$, and visceral metastasis was present in 19 patients (47.5\%). A total of 33 patients $(82.5 \%)$ were strongly positive and $7(17.5 \%)$ were weakly positive for ER expression; a total of 14 patients (35.0\%) were strongly positive and $26(65.0 \%)$ were weakly positive for $\mathrm{PgR}$ expression; a total of 4 patients (10.0\%) were positive and $36(90.0 \%)$ were negative for HER2 expression; as regards Ki67 expression, 7 patients (17.5\%) exhibited high levels and 33 patients (82.5\%) exhibited low levels. Endocrine therapy consisted of letrozole in 22 patients (55.0\%), anastrozole in 11 patients $(27.5 \%)$, tamoxifen \pm luteinizing hormone-releasing hormone agonist in 6 patients (15.0\%), and 
Table I. Demographic data of 40 patients receiving endocrine therapy for stage IV breast cancer.

\begin{tabular}{|c|c|}
\hline Parameters $(n=40)$ & Patient no. $(\%)$ \\
\hline Age (years) & 64 (range, 44-88) \\
\hline \multicolumn{2}{|l|}{ Menopause } \\
\hline Post-/premenopausal & $34(85.0) / 6(15.0)$ \\
\hline \multicolumn{2}{|l|}{ Degree of progression (metastasis) } \\
\hline Bone or soft tissue/visceral & $21(52.5) / 19(47.5)$ \\
\hline \multicolumn{2}{|l|}{ Estrogen receptor } \\
\hline Strongly positive/weakly positive & $33(82.5) / 7(17.5)$ \\
\hline \multicolumn{2}{|l|}{ Progesterone receptor } \\
\hline Strongly positive/weakly positive & $14(35.0) / 26(65.0)$ \\
\hline \multicolumn{2}{|l|}{ HER 2} \\
\hline Negative/positive & $36(90.0) / 4(10.0)$ \\
\hline \multicolumn{2}{|l|}{ Ki67 } \\
\hline$\leq 14 />14 \%$ & $33(82.5) / 7(17.5)$ \\
\hline \multicolumn{2}{|l|}{ Treatment } \\
\hline Letrozole/anastrozole/tamoxifen \pm LHRH agonist/exemestane & $22(55.0) / 11(27.5) / 6(15.0) / 1(2.5)$ \\
\hline \multicolumn{2}{|l|}{ Clinical response } \\
\hline $\mathrm{CR} / \mathrm{PR} / \mathrm{SD} \geq 24$ weeks/SD $<24$ weeks/PD & $0(0.0) / 30(75.0) / 4(10.0) / 2(5.0) / 4(10.0)$ \\
\hline \multicolumn{2}{|l|}{ Clinical response } \\
\hline $\mathrm{ORR} / \mathrm{CBR} / \mathrm{DCR}$ & $30(75.0) / 30(85.0) / 4(90.0)$ \\
\hline
\end{tabular}

HER2, human epidermal growth factor receptor 2; LHRH, luteinizing hormone-releasing hormone; pCR, pathological complete response; $\mathrm{CR}$, complete response; PR, partial response; $\mathrm{SD}$, stable disease; $\mathrm{PD}$, progressive disease; ORR, objective response rate; CBR, clinical benefit response; DCR, disease control rate.
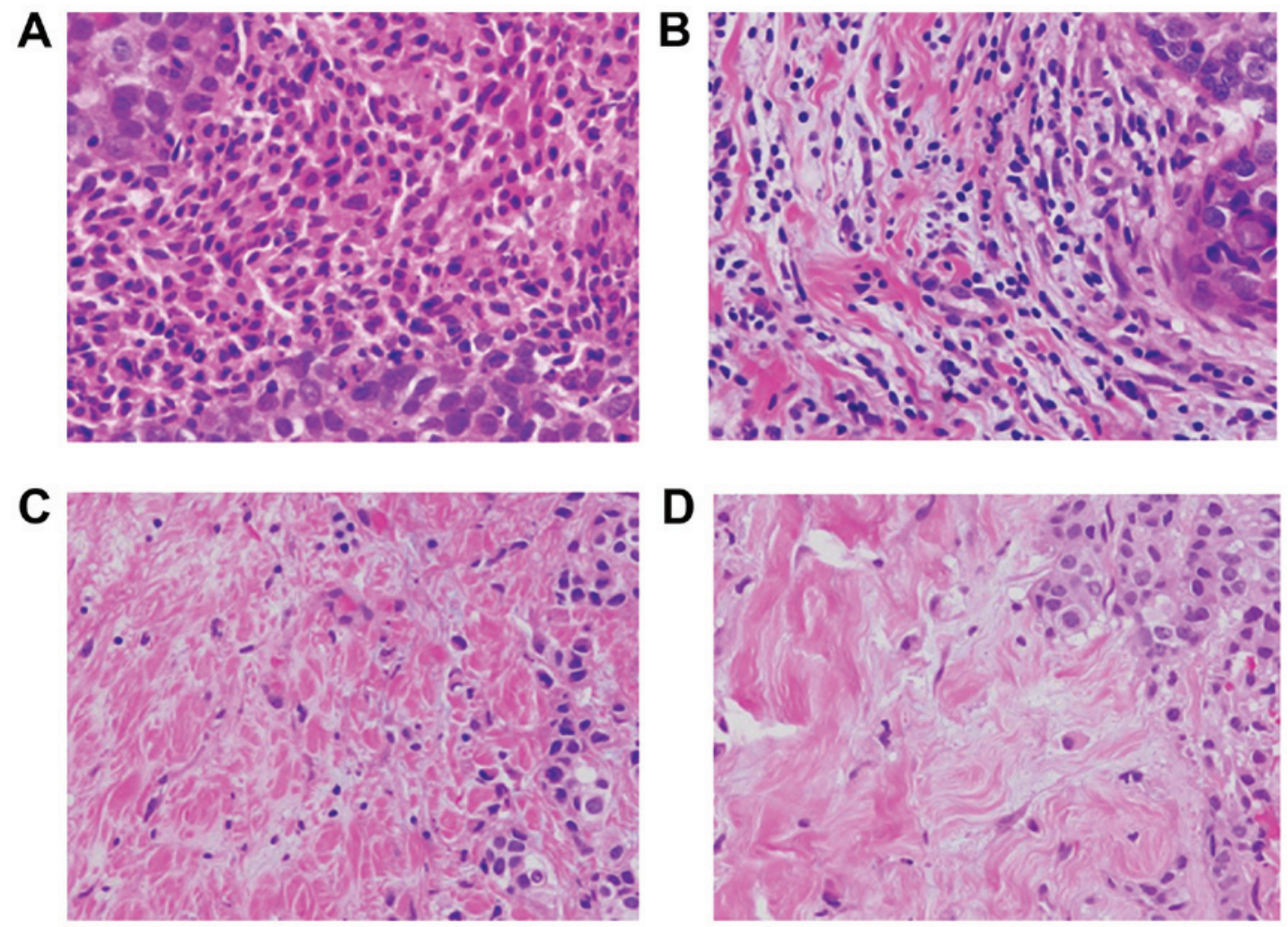

Figure 1. Histopathological TIL evaluation. TILs were measured by examining the occupation ratio of immune cells present in the tumor stroma of hematoxylin and eosin-stained specimens at a magnification, $\mathrm{x} 400$. Proportional scores of 3,2,1 and 0 were assigned if the area of stroma containing lymphoplasmacytic infiltration around invasive tumor cell nests comprised (A) $>50 \%$, (B) $10-50 \%$, (C) $\leq 10 \%$ and (D) $0 \%$, respectively, of the total area. 
Table II. Correlation of clinicopathological characteristics with TILs and LPBC in 40 stage IV breast cancer patients.

\begin{tabular}{|c|c|c|c|c|c|c|}
\hline \multirow[b]{2}{*}{ Parameters } & \multicolumn{2}{|c|}{ TILs, n (\%) } & \multirow[b]{2}{*}{ P-value } & \multicolumn{2}{|c|}{ LPBC, n (\%) } & \multirow[b]{2}{*}{ P-value } \\
\hline & High $(n=13)$ & Low $(\mathrm{n}=27)$ & & LPBC $(n=9)$ & Non-LPBC $(n=31)$ & \\
\hline \multicolumn{7}{|l|}{ Age at surgery, years } \\
\hline$\leq 64$ & $7(53.8)$ & $14(51.9)$ & 0.906 & $7(77.8)$ & $14(45.2)$ & 0.088 \\
\hline$>64$ & $6(46.2)$ & $13(48.1)$ & & $2(22.2)$ & $17(54.8)$ & \\
\hline \multicolumn{7}{|l|}{ Menopausal status } \\
\hline Premenopausal & $2(15.4)$ & $4(14.8)$ & 0.649 & $2(22.2)$ & $4(12.9)$ & 0.410 \\
\hline Postmenopausal & $11(84.6)$ & $23(85.2)$ & & $7(77.8)$ & $27(87.1)$ & \\
\hline \multicolumn{7}{|l|}{ Estrogen receptor } \\
\hline Strongly positive & $9(69.2)$ & $24(88.9)$ & 0.139 & $7(77.8)$ & $26(83.9)$ & 0.504 \\
\hline Weakly positive & $4(30.8)$ & $3(11.1)$ & & $2(22.2)$ & $5(16.1)$ & \\
\hline \multicolumn{7}{|l|}{ Progesterone receptor } \\
\hline Strongly positive & $4(30.8)$ & $10(37.0)$ & 0.491 & $4(44.4)$ & $10(32.3)$ & 0.383 \\
\hline Weakly positive & $9(69.2)$ & $17(63.0)$ & & $5(55.6)$ & $21(67.7)$ & \\
\hline \multicolumn{7}{|l|}{ HER 2} \\
\hline Negative & $12(92.3)$ & $24(88.9)$ & 0.608 & $8(88.9)$ & $28(90.3)$ & 0.656 \\
\hline Positive & $1(7.7)$ & $3(11.1)$ & & $1(11.1)$ & $3(9.7)$ & \\
\hline \multicolumn{7}{|l|}{$\mathrm{Ki} 67, \%$} \\
\hline$\leq 14$ & $10(76.9)$ & $23(85.2)$ & 0.408 & $7(77.8)$ & $26(83.9)$ & 0.504 \\
\hline$>14$ & $3(23.1)$ & $4(14.8)$ & & $2(22.2)$ & $5(16.1)$ & \\
\hline \multicolumn{7}{|l|}{ Degree of progression } \\
\hline Bone or soft tissue metastasis & $7(53.8)$ & $14(51.9)$ & 0.906 & $4(44.4)$ & $17(54.8)$ & 0.431 \\
\hline Visceral metastases & $6(46.2)$ & $13(48.1)$ & & $5(55.6)$ & $14(45.2)$ & \\
\hline \multicolumn{7}{|l|}{ Objective response rate } \\
\hline ORR & $9(69.2)$ & $21(77.8)$ & 0.414 & $7(77.8)$ & $23(74.2)$ & 0.601 \\
\hline Non-ORR & $4(30.8)$ & $6(22.2)$ & & $2(22.2)$ & $8(25.8)$ & \\
\hline
\end{tabular}

HER2, human epidermal growth factor receptor 2; ORR, objective response rate; LPBC, lymphocyte-predominant breast cancer; TILs, tumor-infiltrating lymphocytes.

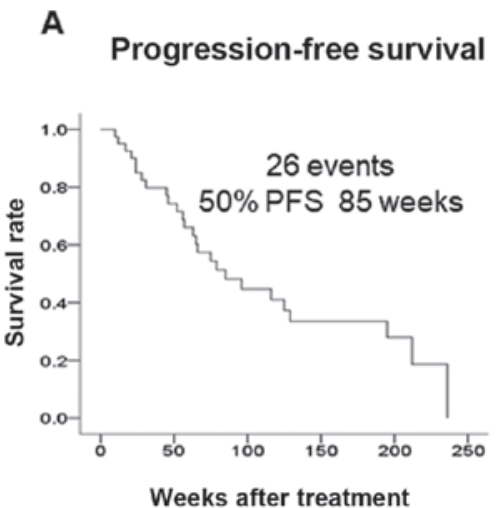

\section{B}

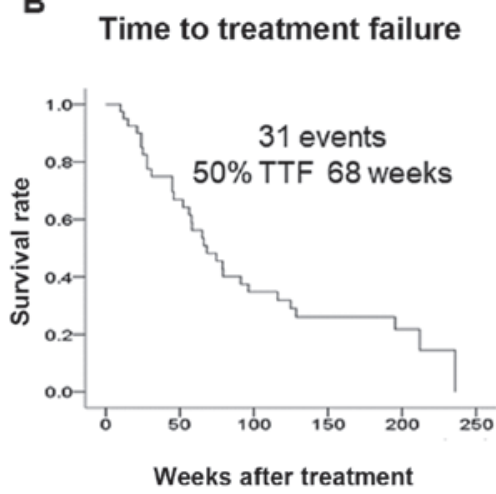

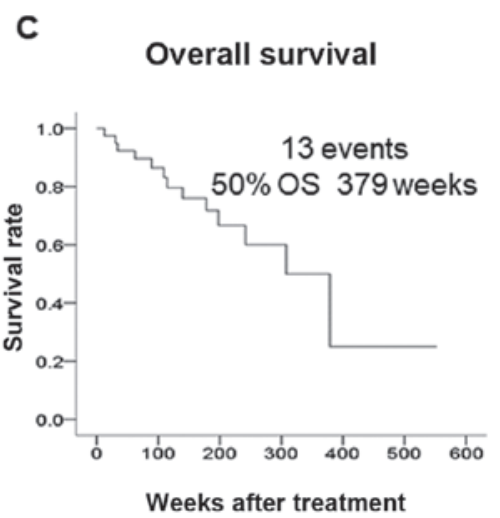

Figure 2. Outcomes of endocrine therapy for stage IV breast cancer. Kaplan-Meier curves of the indicated clinical effects of endocrine therapy are shown. (A) The median PFS was 85 weeks, (B) the median TTF was 68 weeks, and (C) the median OS was 379 weeks. PFS, progression-free survival; TTF, time to treatment failure; OS, overall survival.

exemestane in 1 patient $(2.5 \%)$. As regards tumor response, the ORR was $75.0 \%$, the CBR was $85.0 \%$, and the DCR was $90.0 \%$. The median PFS was 85 weeks, the median TTF was 68 weeks, and the median OS was 379 weeks (Fig. 2).
Prediction of therapeutic effect using TILs. Among the 40 patients, TIL levels were high $(>10 \%)$ in $13(32.5 \%)$ and low $(\leq 10 \%)$ in $27(67.5 \%)$ patients. A total of 9 patients (22.5\%) had LPBC ( $\geq 50 \%$ lymphocyte infiltration), and 
A

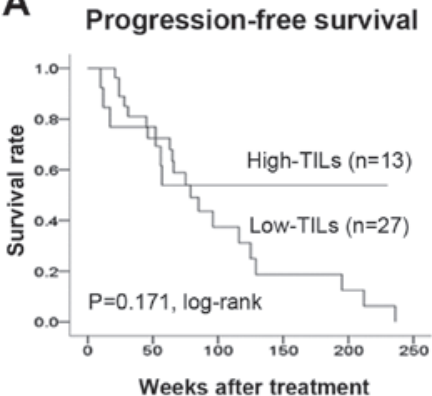

D

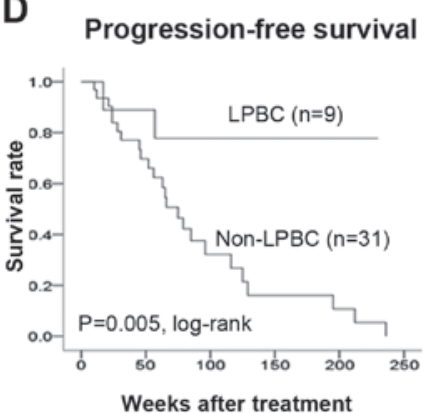

B
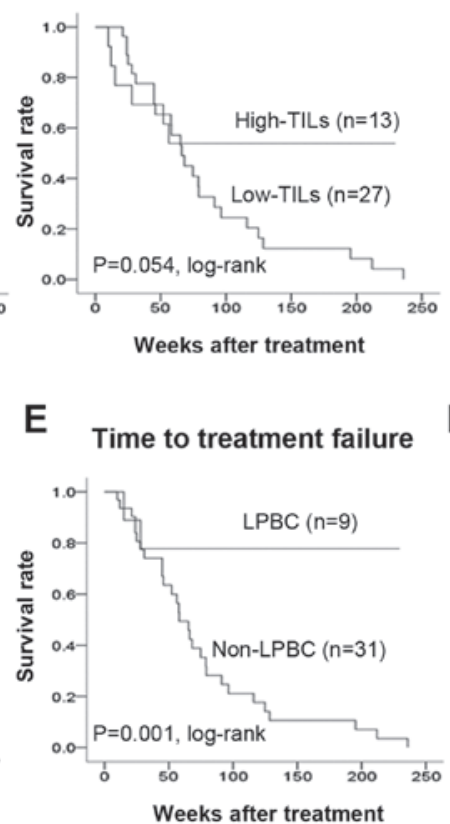

C

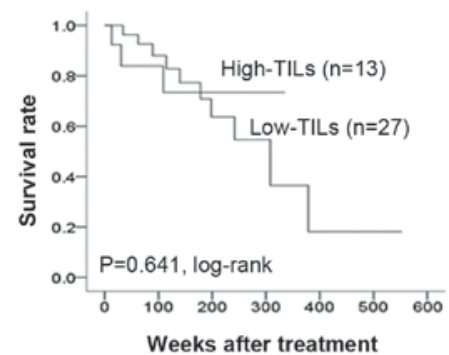

$\mathbf{F}$

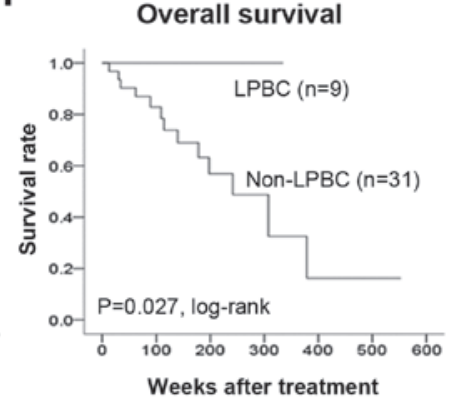

Figure 3. PFS, TTF and OS in stage IV breast cancer according to TIL levels. An analysis of outcomes of the high and low TIL groups revealed no difference in (A) PFS ( $\mathrm{P}=0.171, \log$-rank), (B) TTF ( $\mathrm{P}=0.054, \log$-rank), or (C) OS ( $\mathrm{P}=0.641, \log$-rank) between the two groups. LPBC patients exhibited a significant prolongation of the (D) PFS ( $\mathrm{P}=0.005$, log-rank), (E) TTF ( $\mathrm{P}=0.001$, log-rank) and ( $\mathrm{F}) \mathrm{OS}(\mathrm{P}=0.027$, log-rank) compared to non-LPBC patients. PFS, progression-free survival; TTF, time to treatment failure; OS, overall survival; TILs, tumor-infiltrating lymphocytes; LPBC, lymphocyte-predominant breast cancer.

A

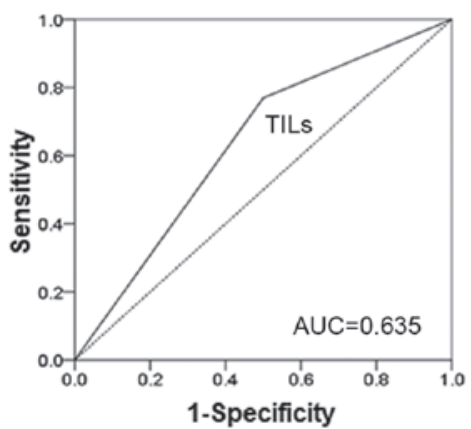

B

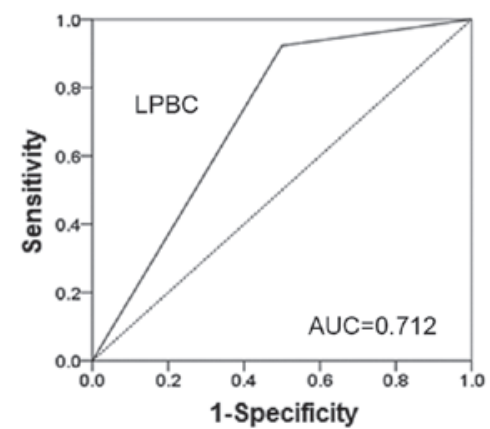

C

Merged

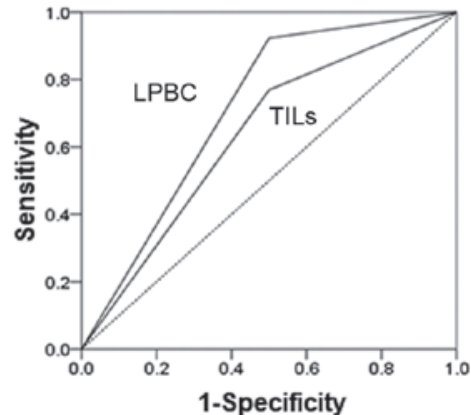

Figure 4. On receiver operating characteristics (ROC) curve analysis, better results were obtained with LPBC (AUC $=0.700)$ than with TILs (AUC $=0.606)$. (A) TILs, (B) LPBCs and (C) merged. AUC, area under the ROC curve; TILs, tumor-infiltrating lymphocytes; LPBC, lymphocyte-predominant breast cancer.

31 patients $(77.5 \%)$ had non-LPBC. Investigation of the clinicopathological characteristics of the patients revealed no significant differences between the high TIL and low TIL groups (Table II). There were also no significant differences between $\mathrm{LPBC}$ and non-LPBC patients. An analysis of outcomes revealed no difference in $\mathrm{PFS}(\mathrm{P}=0.171$, log-rank), TTF ( $\mathrm{P}=0.054$, log-rank), or OS $(\mathrm{P}=0.641, \log$-rank) between the high and low TIL groups (Fig. 3). LPBC patients had significantly prolonged PFS $(\mathrm{P}=0.005, \log$-rank), TTF $(\mathrm{P}=0.001$, log-rank) and $\mathrm{OS}(\mathrm{P}=0.027, \log$-rank) compared with non-LPBC patients. Univariate analysis of PFS found that responding to treatment $(\mathrm{HR}=0.179, \mathrm{P}<0.001)$ and LPBC $(\mathrm{HR}=0.158, \mathrm{P}=0.013)$ were factors associated with a favorable prognosis (Table III). Multivariate analysis confirmed that responding to treatment $(\mathrm{HR}=0.048$,
$\mathrm{P}<0.001)$ and $\mathrm{LPBC}(\mathrm{HR}=0.058, \mathrm{P}=0.001)$ were independent factors associated with a favorable prognosis.

On receiver operating characteristics (ROC) curve analyses, better results were obtained with LPBCs [area under the curve $(\mathrm{AUC})=0.700]$ compared with TILs $(\mathrm{AUC}=0.606)$ (Fig. 4).

\section{Discussion}

The immune system has recently been found to affect the therapeutic efficacy, and it plays an important role in patient prognosis, even in the field of breast cancer $(5,23,24)$. TILs, an indicator for monitoring antitumor immune responses, are reported to be chemosensitive in breast cancers such as TNBC and HER2BC, which display a high degree of immune 
Table III. Univariate and multivariate analysis with respect to progression-free survival in 40 stage IV breast cancer patients.

\begin{tabular}{|c|c|c|c|c|c|c|}
\hline \multirow[b]{2}{*}{ Parameters } & \multicolumn{3}{|c|}{ Univariate analysis } & \multicolumn{3}{|c|}{ Multivariate analysis } \\
\hline & Hazard ratio & $95 \% \mathrm{CI}$ & P-value & Hazard ratio & $95 \% \mathrm{CI}$ & P-value \\
\hline $\begin{array}{l}\text { Age, years } \\
\leq 64 \\
>64\end{array}$ & 1.138 & $0.516-2.511$ & 0.749 & & & \\
\hline $\begin{array}{l}\text { Menopausal status } \\
\text { Premenopausal } \\
\text { Postmenopausal }\end{array}$ & 2.209 & $0.515-9.478$ & 0.286 & & & \\
\hline $\begin{array}{l}\text { Degree of progression } \\
\text { Bone or soft tissue } \\
\text { Visceral metastases }\end{array}$ & 0.605 & $0.271-1.355$ & 0.222 & & & \\
\hline $\begin{array}{l}\text { TILs } \\
\text { High } \\
\text { Low }\end{array}$ & 0.527 & $0.208-1.339$ & 0.178 & & & \\
\hline $\begin{array}{l}\mathrm{Ki} 67, \% \\
\leq 14 \\
>14\end{array}$ & 1.049 & $0.391-2.815$ & 0.925 & 1.578 & $0.540-4.610$ & 0.405 \\
\hline $\begin{array}{l}\text { Response rate } \\
\text { ORR } \\
\text { Non-ORR }\end{array}$ & 0.179 & $0.072-0.443$ & $<0.001$ & 0.048 & 0.011-0.199 & $<0.001$ \\
\hline $\begin{array}{l}\text { LPBC } \\
\text { Yes } \\
\text { No }\end{array}$ & 0.158 & $0.037-0.680$ & 0.013 & 0.058 & $0.010-0.333$ & 0.001 \\
\hline
\end{tabular}

CI, confidence interval; TILs, tumor-infiltrating lymphocytes; ORR, objective response rate; LPBC, lymphocyte-predominant breast cancer.

activity (10,25-27). However, although it is known that there are few TILs in ER-positive breast cancer, the association of these TILs with endocrine therapy has yet to be determined (20).

Cancer cells have various gene abnormalities that allow them to proliferate spontaneously and survive, but they are also affected by the surrounding environment (cancer microenvironment), which is involved in the intrinsic characteristics of cancer (5). On the other hand, the ER, which is crucial for the development and progression of breast cancer, is activated not by estrogen alone, but by a complex signaling cascade, including a pathway that is mediated by growth factor-stimulated phosphorylation, and its regulation depends on the microenvironment surrounding the cancer cells (28). Specifically, even in endocrine therapy, which exerts an antitumor effect by blocking estrogen activity and inhibiting estrogen production, the regulation and improvement of the cancer microenvironment are crucial to therapy. In the present study, it was possible to predict the therapeutic effect of endocrine therapy in LPBC, which displays a high degree of lymphocyte infiltration. In ER-positive breast cancer, due to the small number of TILs, a high degree of lymphocytic infiltration is considered predictive of the therapeutic effect.

In addition, immunogenic cell death (ICD) is induced by both chemotherapy and radiotherapy (29-31). Cancer cells that cause ICD release nucleoproteins, such as high mobility group box 1 protein (HMGB1). HMGB1 acts on toll-like receptor
4, which is expressed on dendritic cells (DC) to induce DC maturation, and promotes antigen presentation and $\mathrm{T}$-cell activation (32). In this manner, anticancer treatments markedly affect the immune response of the body, and it is believed that an immune response is activated by a similar mechanism in endocrine therapy as well. The present findings suggest that LPBC patients, who display a high level of immunoactivity, respond to treatment with a greater level of sensitivity, as the tumor immune microenvironment is modulated by endocrine therapy.

In the present study, confirmation of LPBC by evaluating TILs in biopsy samples in stage IV breast cancer was found to contribute to the selection of the appropriate initial drug therapy. However, the fact that this was a small-scale retrospective study is a major limitation. It will be necessary to perform future analyses of subsets of TILs and to verify the immunologically relevant genes involved in endocrine therapy. In the future, it is expected that the suitability of LPBC as a predictive factor of therapeutic efficacy will be investigated in other studies, including the PROACT study, in which neoadjuvant endocrine therapy is currently being investigated, as well as in the ACOSOG Z1031 study (4,33).

The findings of the present study suggest that a high level of lymphocytic infiltration in the tumor stroma may serve as a predictor of the therapeutic efficacy of endocrine therapy for patients with stage IV ER-positive breast cancer. 


\section{Acknowledgements}

The authors would like to thank Yayoi Matsukiyo and Tomomi Okawa (Department of Breast and Endocrine Surgery, Osaka City University Graduate School of Medicine) for their helpful advice regarding data management.

\section{Funding}

The present study was supported by grants from the Japan Society for the Promotion of Science (KAKENHI; nos. 19K18038, 26461957 and 17K10559). The funding source had no role in the design of the study, the collection, analysis and interpretation of the data, or the writing of this manuscript.

\section{Availability of data and materials}

The datasets used and/or analyzed during the present study are available from the corresponding author on reasonable request.

\section{Authors' contributions}

YA participated in the design of the study and drafted the manuscript. SK participated in the design of the study and manuscript editing. WG, KoT, MS, RA and TT helped with data collection and manuscript preparation. KaT and ST helped with study data collection and participated in its design. $\mathrm{KH}$ and MO conceived the study, participated in its design and coordination, and helped to draft the manuscript. All authors have read and approved the final manuscript.

\section{Ethics approval and consent to participate}

This research conformed to the provisions of the Declaration of Helsinki, 2013. All patients were informed of the investigational nature of this study and provided their written, informed consent. The study protocol was approved by the Ethics Committee of Osaka City University (approval no. 926).

\section{Patient consent for publication}

Not applicable.

\section{Competing interests}

The authors declare that they have no competing interests.

\section{References}

1. Andre F, Slimane K, Bachelot T, Dunant A, Namer M, Barrelier A, Kabbaj O, Spano JP, Marsiglia H, Rouzier R, et al: Breast cancer with synchronous metastases: Trends in survival during a 14-year period. J Clin Oncol 22: 3302-3308, 2004.

2. Hortobagyi GN: Treatment of breast cancer. N Engl J Med 339: 974-984, 1998

3. Ellis MJ, Tao Y, Luo J, A'Hern R, Evans DB, Bhatnagar AS, Chaudri Ross HA, von Kameke A, Miller WR, Smith I, et al: Outcome prediction for estrogen receptor-positive breast cancer based on postneoadjuvant endocrine therapy tumor characteristics. J Natl Cancer Inst 100: 1380-1388, 2008.
4. Ellis MJ, Suman VJ, Hoog J, Lin L, Snider J, Prat A, Parker JS, Luo J, DeSchryver K, Allred DC, et al: Randomized phase II neoadjuvant comparison between letrozole, anastrozole, and exemestane for postmenopausal women with estrogen receptor-rich stage 2 to 3 breast cancer: Clinical and biomarker outcomes and predictive value of the baseline PAM50-based intrinsic subtype-ACOSOG Z1031. J Clin Oncol 29: 2342-2349, 2011.

5. Hanahan D and Weinberg RA: Hallmarks of cancer: The next generation. Cell 144: 646-674, 2011.

6. Zitvogel L, Kepp O and Kroemer G: Immune parameters affecting the efficacy of chemotherapeutic regimens. Nat Rev Clin Oncol 8: 151-160, 2011.

7. Dougan M and Dranoff G: Immune therapy for cancer. Annu Rev Immunol 27: 83-117, 2009.

8. Adams S, Gray RJ, Demaria S, Goldstein L, Perez EA, Shulman LN, Martino S, Wang M, Jones VE, Saphner TJ, et al: Prognostic value of tumor-infiltrating lymphocytes in triple-negative breast cancers from two phase III randomized adjuvant breast cancer trials: ECOG 2197 and ECOG 1199. J Clin Oncol 32: 2959-2966, 2014

9. Denkert C, von Minckwitz G, Brase JC, Sinn BV, Gade S, Kronenwett R, Pfitzner BM, Salat C, Loi S, Schmitt WD, et al: Tumor-infiltrating lymphocytes and response to neoadjuvant chemotherapy with or without carboplatin in human epidermal growth factor receptor 2-positive and triple-negative primary breast cancers. J Clin Oncol 33: 983-991, 2015.

10. Savas P, Salgado R, Denkert C, Sotiriou C, Darcy PK, Smyth MJ and Loi S: Clinical relevance of host immunity in breast cancer: From TILs to the clinic. Nat Rev Clin Oncol 13: 228-241, 2016.

11. Asano Y, Kashiwagi S, Goto W, Kurata K, Noda S, Takashima T, Onoda N, Tanaka S, Ohsawa M and Hirakawa K: Tumour-infiltrating CD8 to FOXP3 lymphocyte ratio in predicting treatment responses to neoadjuvant chemotherapy of aggressive breast cancer. Br J Surg 103: 845-854, 2016.

12. Asano Y, Kashiwagi S, Onoda N, Kurata K, Morisaki T, Noda S, Takashima T, Ohsawa M, Kitagawa S and Hirakawa K: Clinical verification of sensitivity to preoperative chemotherapy in cases of androgen receptor-expressing positive breast cancer. Br J Cancer 114: 14-20, 2016.

13. Asano Y, Kashiwagi S, Onoda N, Noda S, Kawajiri H, Takashima T, Ohsawa M, Kitagawa S and Hirakawa K: Predictive value of neutrophil/lymphocyte ratio for efficacy of preoperative chemotherapy in triple-negative breast cancer. Ann Surg Oncol 23: 1104-1110, 2016.

14. Asano Y, Kashiwagi S, Onoda N, Noda S, Kawajiri H, Takashima T, Ohsawa M, Kitagawa S and Hirakawa K: Platelet-lymphocyte ratio as a useful predictor of the therapeutic effect of neoadjuvant chemotherapy in breast cancer. PLoS One 11: e0153459, 2016.

15. Greene FL and Sobin LH: A worldwide approach to the TNM staging system: Collaborative efforts of the AJCC and UICC. J Surg Oncol 99: 269-272, 2009.

16. Goldhirsch A, Wood WC, Coates AS, Gelber RD, Thürlimann B and Senn HJ; Panel members: Strategies for subtypes-dealing with the diversity of breast cancer: Highlights of the St. Gallen International Expert Consensus on the Primary Therapy of Early Breast Cancer 2011. Ann Oncol 22: 1736-1747, 2011.

17. Eisenhauer EA, Therasse P, Bogaerts J, Schwartz LH, Sargent D, Ford R, Dancey J, Arbuck S, Gwyther S, Mooney M, et al: New response evaluation criteria in solid tumours: Revised RECIST guideline (version 1.1). Eur J Cancer 45: 228-247, 2009.

18. Salgado R, Denkert C, Demaria S, Sirtaine N, Klauschen F, Pruneri G, Wienert S, Van den Eynden G, Baehner FL, Penault-Llorca F, et al: The evaluation of tumor-infiltrating lymphocytes (TILs) in breast cancer: Recommendations by an International TILs Working Group 2014. Ann Oncol 26: 259-271, 2015.

19. Ono M, Tsuda H, Shimizu C, Yamamoto S, Shibata T, Yamamoto H, Hirata T, Yonemori K, Ando M, Tamura K, et al: Tumor-infiltrating lymphocytes are correlated with response to neoadjuvant chemotherapy in triple-negative breast cancer. Breast Cancer Res Treat 132: 793-805, 2012.

20. Mao Y, Qu Q, Zhang Y, Liu J, Chen X and Shen K: The value of tumor infiltrating lymphocytes (TILs) for predicting response to neoadjuvant chemotherapy in breast cancer: A systematic review and meta-analysis. PLoS One 9: e115103, 2014.

21. Loi S: Host antitumor immunity plays a role in the survival of patients with newly diagnosed triple-negative breast cancer. J Clin Oncol 32: 2935-2937, 2014. 
22. McShane LM, Altman DG, Sauerbrei W, Taube SE, Gion M and Clark GM; Statistics Subcommittee of the NCI-EORTC Working Group on Cancer Diagnostics: Reporting recommendations for tumor marker prognostic studies. J Clin Oncol 23: 9067-9072, 2005.

23. Couzin-Frankel J: Breakthrough of the year 2013. Cancer immunotherapy. Science 342: 1432-1433, 2013.

24. Fridman WH, Pages F, Sautes-Fridman C and Galon J: The immune contexture in human tumours: Impact on clinical outcome. Nat Rev Cancer 12: 298-306, 2012.

25. Liu H, Zhang T, Ye J, Li H, Huang J, Li X, Wu B, Huang X and Hou J: Tumor-infiltrating lymphocytes predict response to chemotherapy in patients with advance non-small cell lung cancer. Cancer Immunol Immunother 61: 1849-1856, 2012.

26. Kocián P, Šedivcová M, Drgáč J, Cerná K, Hoch J, Kodet R, Bartůňková J, Spíšek R and Fialová A: Tumor-infiltrating lymphocytes and dendritic cells in human colorectal cancer: Their relationship to KRAS mutational status and disease recurrence. Hum Immunol 72: 1022-1028, 2011.

27. Lee WS, Kang M, Baek JH, Lee JI and Ha SY: Clinical impact of tumor-infiltrating lymphocytes for survival in curatively resected stage IV colon cancer with isolated liver or lung metastasis. Ann Surg Oncol 20: 697-702, 2013.

28. Omoto Y, Eguchi H, Yamamoto-Yamaguchi Y and Hayashi S: Estrogen receptor (ER) beta1 and ERbetacx/beta2 inhibit ERalpha function differently in breast cancer cell line MCF7. Oncogene 22: 5011-5020, 2003.

29. Kroemer G, Galluzzi L, Kepp O and Zitvogel L: Immunogenic cell death in cancer therapy. Annu Rev Immunol 31: 51-72, 2013.

30. Tesniere A, Panaretakis T, Kepp O, Apetoh L, Ghiringhelli F, Zitvogel L and Kroemer G: Molecular characteristics of immunogenic cancer cell death. Cell Death Differ 15: 3-12, 2008.
31. Kono K, Mimura K and Kiessling R: Immunogenic tumor cell death induced by chemoradiotherapy: Molecular mechanisms and a clinical translation. Cell Death Dis 4: e688, 2013.

32. Yamazaki T, Hannani D, Poirier-Colame V, Ladoire S, Locher C, Sistigu A, Prada N, Adjemian S, Catani JP, Freudenberg M, et al: Defective immunogenic cell death of HMGB1-deficient tumors: Compensatory therapy with TLR4 agonists. Cell Death Differ 21: 69-78, 2014

33. Cataliotti L, Buzdar AU, Noguchi S, Bines J, Takatsuka Y, Petrakova K, Dube P and de Oliveira CT: Comparison of anastrozole versus tamoxifen as preoperative therapy in postmenopausal women with hormone receptor-positive breast cancer: The Pre-Operative 'Arimidex' Compared to Tamoxifen (PROACT) trial. Cancer 106: 2095-2103, 2006.

c) (7) (8) This work is licensed under a Creative Commons Attribution-NonCommercial 4.0 International (CC BY-NC 4.0) License. 